\title{
ETAT MARBRE
}

\section{BY}

\section{A. MEYER AND L. C. COOK, London*}

The condition known as état marbré was first described fully by C. Vogt 24 in 1911 under the name of status marmoratus and has since been the subject of considerable interest and study. Nevertheless no full description has as yet appeared in any English journal, and therefore a brief introductory summary of the main clinical and pathological features may not come amiss.

On the clinical side, the condition usually manifests itself from earliest infancy, development is retarded and more or less severe mental defect is of constant appearance. The picture is one of double choreoathetosis, sometimes combined with epilepsy. Loss of emotional control is a prominent feature, and inability to use the muscles of expression and articulation sometimes occurs. In the majority of cases the condition remains stationary ; in others severe generalized paralysis, often with torsion spasm and other contractures, eventually supervenes, and death occurs before or during early adult life. Pathologically the most striking feature is the peculiar marblelike appearance of certain areas of the striate body and to a lesser degree of other parts of the brain. The clinical picture, sometimes known as Vogt's disease, is considered by some to be sufficiently characteristic to be diagnosed during life, but, as we shall point out later, there are reasons for believing that the condition is not a clear-cut clinical or pathological entity.

Although uncommon, the condition is probably not so rare as might at first appear. It is probable that the majority of cases have failed to come under the care of competent neurologists ; some may have been attributed to meningitis or encephalitis lethargica, while others have almost certainly been overlooked in institutions or elsewhere amongst a mass of heterogeneous cerebral palsies of childhood.

\section{PERSONAL GASES}

Case I.-D.L., a girl, age two and a half years, was admitted to the Fountain Hospital for mental defectives on August 13, 1920.

History.-Unfortunately the history of this case is very scanty, as there was no opportunity of interviewing the relatives personally and, since the patient's death, they have persistently ignored all letters. Except for some evidence of tuberculosis and paralysis on the paternal side, there is no family history of note. The patient was

* From the Central Pathological Laboratories of the London County Mental Hospitals. 
the second of three siblings. No history regarding the periods of pregnancy, birth or early infancy is available.

State on Admission.-She was quite helpless and showed no signs of possessing any intelligence. She could not recognize nurses attending her, nor did she take any interest in her surroundings. Paresis of legs was noted.

Progress.-In March, 1924, she had her first epileptiform fit, and in the following month she contracted measles. In August, 1927, it was reported that she exhibited occasional coarse tremors, but had had no recent fits. Her habits were then clean, but she had to be hand-fed. A year later she was described as a case of spastic paraplegia with choreiform movements, faulty in habits and needing every attention. In January, 1931, her choreoathetotic movements were noted to be getting more severe, but she had had no fits for five years. In the following year, at the age of 13 , she began to have frequent screaming attacks for no apparent reason. In June, 1932, she became more helpless and had to lie either in bed or in a special large 'basket,' as she could not sit up. Athetotic and choreic movements were much worse, although the screaming fits were less frequent. During these years she had made some intellectual progress and although she was never able to articulate, she understood what was said to her fairly well, liked to be ' made a fuss of,' smiled when her favourites approached her and could make affirmative and negative noises. Paralysis and wasting of her legs and left arm, and torsion-spasm of her trunk had been steadily progressing and were now extremely severe.

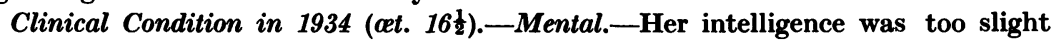
for tests to serve any useful purpose. She could not speak, but understood fairly well. She turned her eyes and tried to point in the direction of named nurses or patients in the ward. She took a considerable interest in her surroundings and became upset and emotional if she were not greeted by visitors to the ward. No screaming fits occurred, but she cried a good deal, often for no apparent reason. She was incontinent and altogether helpless.

Physical.-Her appearance was that of an emaciated girl of 12 years. Sexual development was slight, but some pubic and axillary hair was present. Menstruation never occurred. Her expression was strained and rather mask-like. Her smile dawned slowly and became wide and fixed and her facial appearance was characteristic of an extrapyramidal lesion.

Paralysis and Contractures.-There was extreme and generalized muscular wasting and weakness. Torsion contracture had reached a very severe degree; the thorax was grossly deformed, lateral curvature of the spine with convexity to the right being especially severe. The head was rotated to the left and the pelvis drawn upwards and to the left. Both legs showed adduction spasm, with the knees in contact and the feet widely separated. The arms also showed severe contractures, with flexion at the elbow joints, everted forearms and claw hands. Tendon reflexes were very brisk everywhere. On the left side there was an extensor plantar reflex; the right foot was too contracted for any plantar reflex to be elicited. The pupils reacted to light and on accommodation and the fundi were normal.

No fits or choreic movements had occurred recently and there was no evidence of myoclonus at any time since admission.

She gradually became weaker, terminal bronchitis and pulmonary congestion setting in a fortnight before her death (November 11, 1934).

\section{PATHOLOGIGAL EXAMINATION}

Lungs.-Signs of bronchitis and terminal basal congestion were present. Heart. - The muscle was pale and flabby, the right ventricle somewhat dilated and the left ventricle hypertrophied. The valves were normal. 
Liver.-There was considerable venous congestion and some degree of fibrosis round the bile ducts.

The pancreas and pituitary body showed more fibrous interstitial tissue than is usual and the spleen was congested; otherwise these organs, and also the thyroid, suprarenals and kidneys were normal, both to naked eye and microscopical examination.

Brain.-Weight, 1,006 gm. Macroscopical examination.-The surface of the brain did not show any gross changes. Coronal sections revealed a symmetrical process in the striate body, involving both the caudate nucleus and the putamen. Both these nuclei contained whitish foci, which were connected with each other. The globus pallidus appeared to be intact. The reticulate zone of the substantia nigra showed a brownish discolouration, but no melanin pigment was detectable in the zona compacta. The hila of the

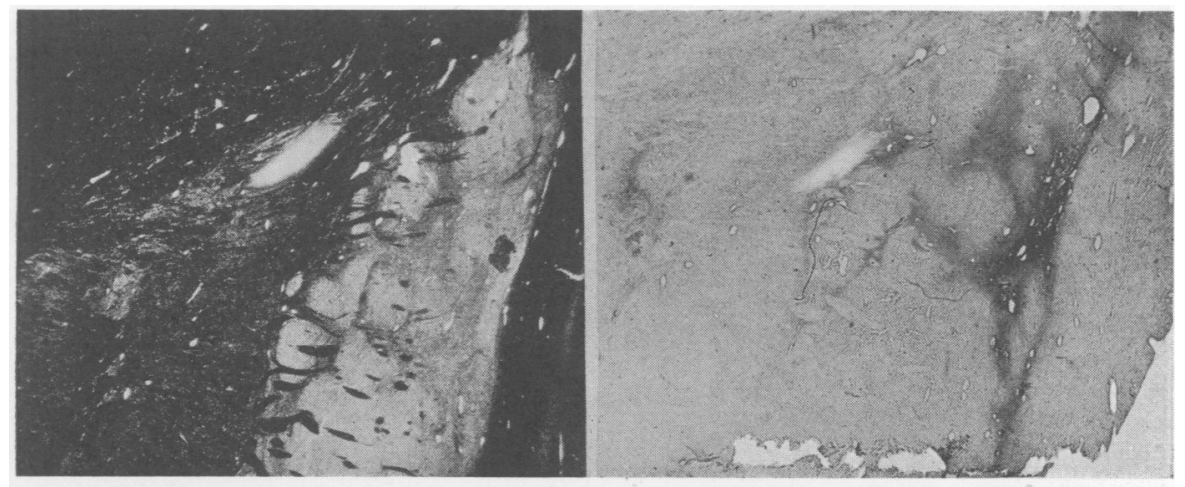

(a)

(b)

FIG. 1.- 'Marble state.' (a) Spielmeyer's myelin stain ; (b) Holzer's glia stain. $\quad \times 7$

dentate nuclei of the cerebellum and the inferior olivary bodies were also of a brownish colour. The rest of the brain showed no noteworthy macroscopic changes.

Histological Findings.-Corpus striatum.-Myelin pictures of the striate body showed a symmetrical ' marble state' in the dorsolateral parts of the putamen and the internal part of the caudate nucleus (fig. $1 a$ ). In appearance and degree the marbling was somewhat similar to that of the fourth case of $\mathrm{C}$. and $\mathrm{O}$. Vogt. ${ }^{23}$ Holzer's stain revealed that the hypermyelinized areas corresponded entirely with the glial scars (fig. $1 b$ ), and there was unmistakable evidence that these scars completely covered the field taken by the hypermyelinized foci. In many parts of the affected areas the ganglioncells had disappeared. In Nissl sections the glial proliferation was not sufficiently well marked to give any idea of the intensity of the process. The glial fibrous scarring was very dense, the individual fibres being rather delicate. The vessels showed fibrotic proliferation of the walls, but neither 
here nor elsewhere were there any signs of recent activity of the process. The myelin-fibres of the scars intertwined very densely. The hypermyelinized fibres were usually delicate and showed frequent thickenings and end-bulbs, but no loops.

Several points of special interest arise from the examination of these sections. First, the external capsule was seen to be changed into a strip of dense glial fibrosis, the scars of the 'marble state' often constituting only a ramification of this more massive scar (fig. $1 b$ ). The scar in the external capsule extended irregularly and to a lesser degree into the claustrum and capsula extrema. Less frequently a similar picture was evident at the margin between the external capsule and the caudate nucleus.

Secondly, the large striopallidal fibres were not involved and could be

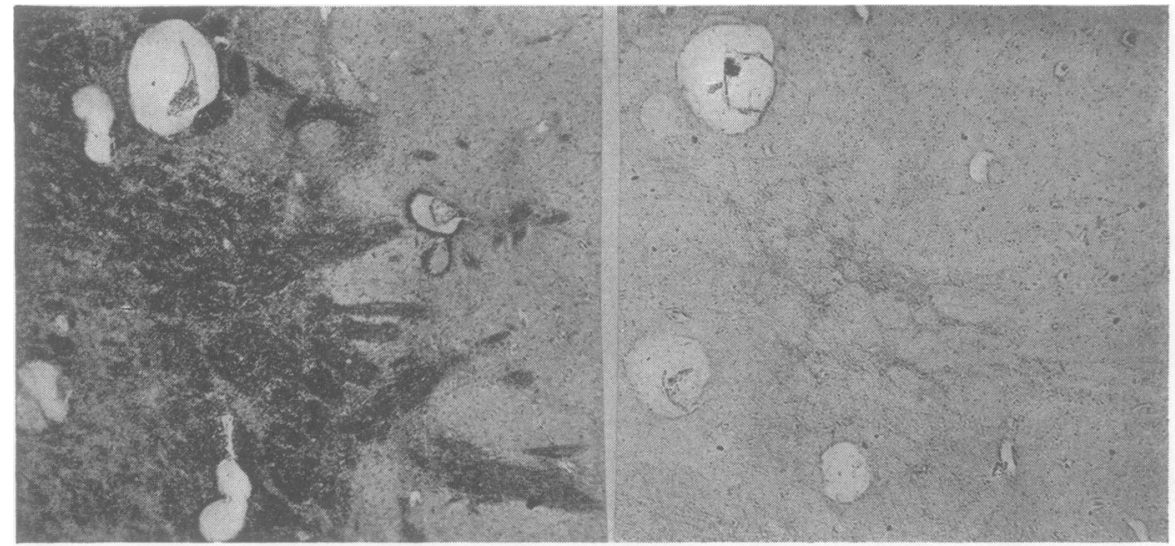

(a)

(b)

Fig. 2.-Network-like glial scars at the junction of putamen and globus pallidus. (a) Spielmeyer's myelin stain ; (b) Holzer's stain. $\times 20$.

seen, often in large numbers, lying intact within the scar tissue. The ansa lenticularis, as well as the lamellæ of the globus pallidus, was sclerosed. The scarring of the external lamella was in some places connected with the ' marbled' scars of the putamen. At the junction of the putamen and the globus pallidus, network-like ramifications of glial scars could frequently be observed (fig. 2). This retiform structure was brought about by the glial scar tissue expanding round the transversely or obliquely cut large striopallidal bundles, which again were spared. This network had a superficial resemblance to the état marbré, but it was of much smaller size and was not hypermyelinized.

In the dorsal parts of the globus pallidus were scattered patches of demyelinization with corresponding gliosis, frequently showing a perivascular distribution. The ganglion-cells did not show any remarkable changes, but some of the macroglia cells were hypertrophied, although they never reached 
the size of the Alzheimer type of cell. No increase of pigment could be detected with Nissl, fat or iron stain, nor were there any 'pseudo-calcium' deposits either within or outside the vessel walls.

Thalamus and Hypothalamic Regions.-There was a marked subependymal glial sclerosis at the surface of the thalamus, with particular accentuation in the region of the terminal vein. The corpus Luysii was only slightly decreased in size and Forel's field was sclerosed.

Substantia nigra.-In both the compact and reticulate zones of the substantia nigra a well-marked glial sclerosis was seen. In the reticulate zone Nissl's stain revealed a definite increase in the greenish, bluish and brownish

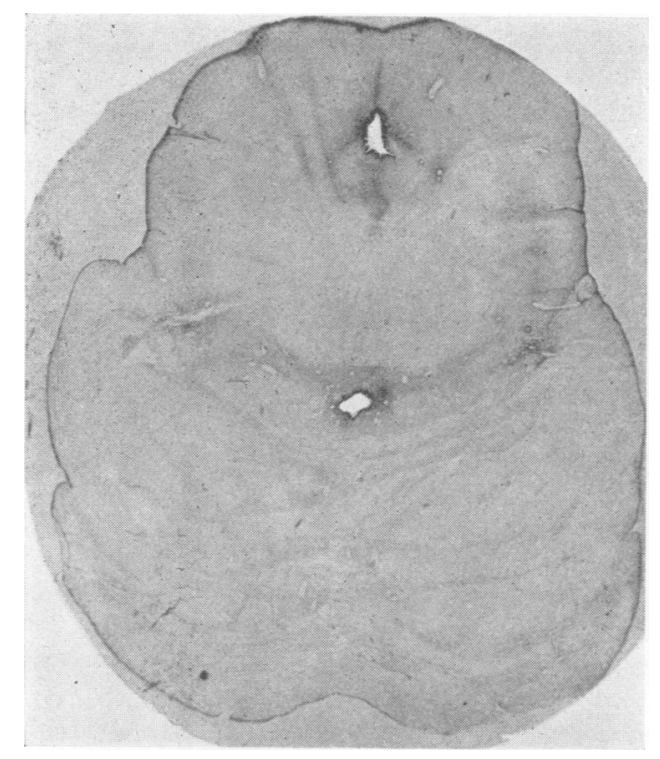

Fra. 3.-Pons. Holzer's glia stain. $\times 3$.

pigment described by Hallervorden and Spatz. ${ }^{26}$ It was situated in the glial and compound granular cells and as free-lying globules, particularly near the vessels. It gave only a partial iron reaction (after being fixed in formalin for a long period) and rarely stained with Scharlach $\mathbf{R}$. The amount of pigment although considerable fell far short of that of the original case of Hallervorden and Spatz. In the compact zone melanin was entirely absent from the ganglion cells, although the cells themselves were still present. With reference to Helfand's ${ }^{25}$ recent findings in état dysmyelinisé, it may be mentioned that melanin was present in normal quantity and quality in the locus cœruleus and dorsal nucleus of the vagus nerve.

Midbrain.-Around the aqueduct and the foramen cæcum there was a fairly heavy gliosis (fig. 3). From the foramen cæcum it extended symmetrically on both sides in a wing-like manner just below the mesial fillets. In 
the lateral part of this scar there was again a network arrangement round the transversely cut, well-preserved myelin bundles (fig. 4). Within the brachia

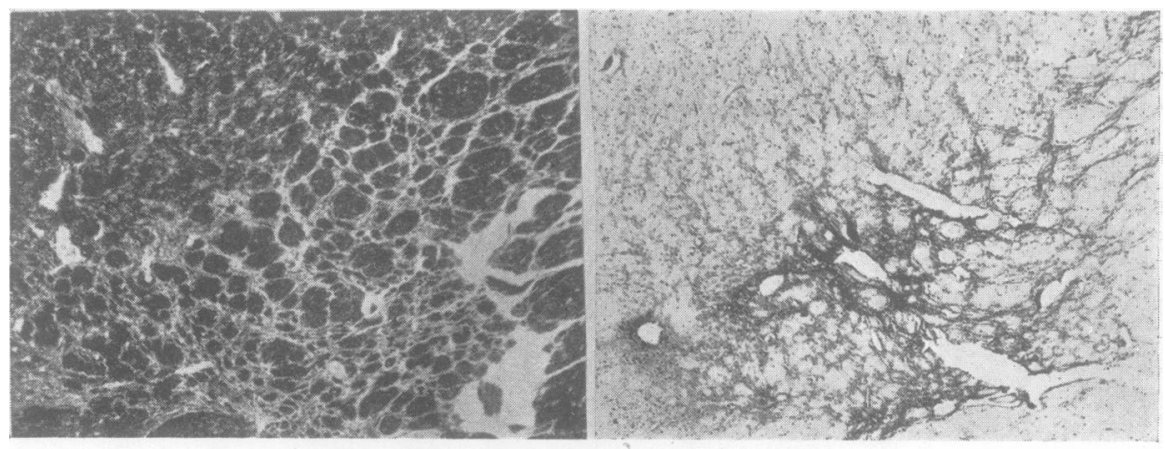

(a)

(b)

Fig. 4.-Pons, dorsolateral part of the pes, showing glial scars round preserved fibre bundles. (a) Spielmeyer's myelin stain; (b) Holzer's stain. $\times 18$

conjunctiva the tendency to decolourize the myelin dye was abnormally great, although neither definite demyelinization nor glial sclerosis was found.

Medulla oblongata. - The floor of the fourth ventricle and the hila of both the olivary bodies showed considerable gliosis. There was no dropping out of the ganglion cells, but they showed, as they frequently do, increased deposits of lipofuscin.

Cerebellum.-The hilum of the dentate nucleus was almost completely

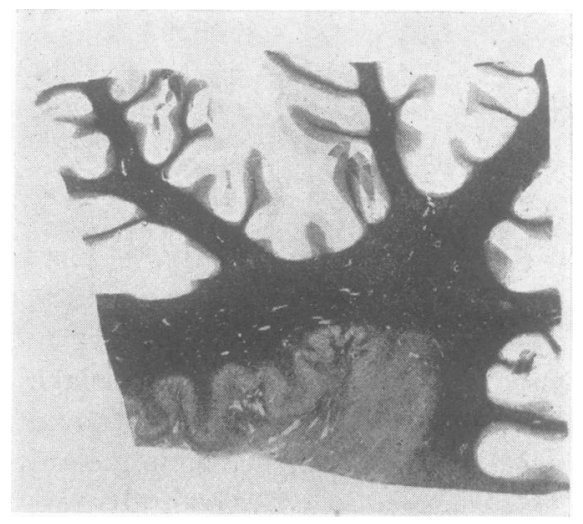

FiG. 5.-Demyelinization in the region of the dentate nucleus. Spielmeyer's myelin stain. $\times 3$.

demyelinized (fig. 5), and showed corresponding glial proliferation, although the strands of ganglion-cells appeared to be well preserved. In the rest of the cerebellar white matter there was also a delicate fibrous glial prolifera- 
tion, associated with a slight and sometimes patchy reduction in staining power of the myelin sheaths. Sections of the axis-cylinders did not reveal any marked change.

Cerebral White Matter.-The same diffuse or patchy inability to take up the hæmatoxylin of the myelin stains was observed in widespread areas of the cerebral white matter, frequently associated with a slight glial proliferation. Particularly well marked was the demyelinization of the white matter in the occipital lobe, with preservation of the arcuate fibres. Throughout the cerebral and cerebellar cortex no noteworthy changes occurred except for a diffuse subpial gliosis.

Case II.-M.E.R., a woman, aged 42 years, was admitted to Leavesden Menta Hospital on January 29, 1932. This case will be clinically and pathologically described

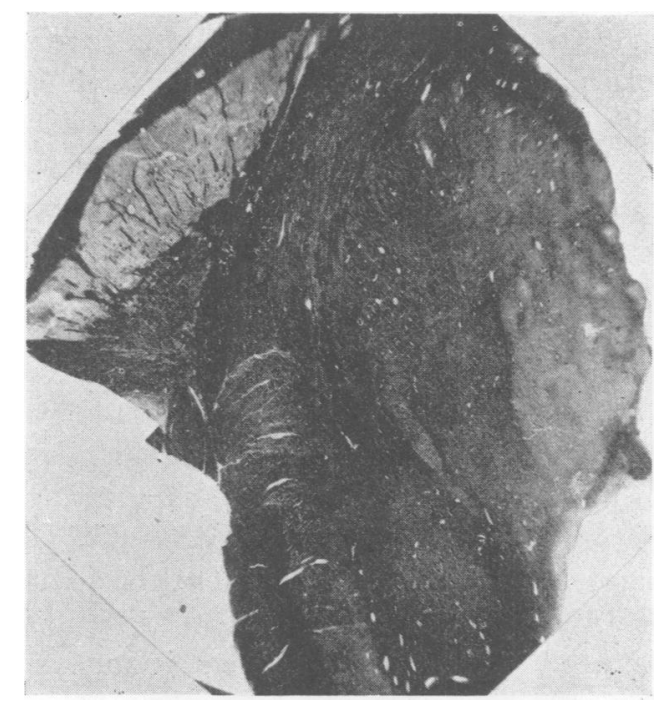

Fig. 6.-Etat marbré of the thalamus. Spielmeyer's myelin stain. $\times 2 \frac{1}{2}$.

in full in a further paper, but certain features must be mentioned here, because of their important bearing on our present subject. Most remarkable of all was the appearance of a network of hypermyelinized glial scars in the medial nucleus of the thalamus (fig. 6), although there was no actual 'marble state' of the corpus striatum. In addition to this there were several points of resemblance to our first case, including a sclerosis of the external capsule and ansa lenticularis, an increase of pigment in the globus pallidus and reticulate zone of the substantia nigra (which also showed a heavy sclerosis), general subependymal sclerosis, demyelinization of the hilum of the dentate nucleus and, in a patchy manner, of the cerebellar white matter, sclerosis of the hila of the olivary bodies and, finally, a diminution in the capacity of the cerebral white matter to take up stain.

Clinically the patient suffered from mental defect and cerebral diplegia from earliest infancy. She was able to walk at the age of five years, but became paralysed during adolescence and died at the age of 44 years in a state of idiocy and generalized spasticity. 


\section{DISGUSSION}

The pathological findings in our first case leave no room for doubt as to its identity with those previously described as état marbré. Apart from the glial scars, it was possible to demonstrate foci of hypermyelinization, typically distributed, in the putamen and caudate nucleus. Moreover, in contradistinction to the findings of Case, ${ }^{4}$ the hypermyelinized foci and the glial scars could be shown to occupy identical areas. In this connexion it may be mentioned that the ' marbling' is not visible with the same intensity in every section or even in neighbouring sections, which may account for the difficulty in demonstrating the identity of the sites of marbling in glial and myelin pictures in some cases.

Both in Case I of this paper and in A. Meyer's ${ }^{12}$ previous case there was a considerable sclerosis of the external capsule, extending to a lesser degree towards the region of the claustrum and the capsula extrema. This scar was present also in other published cases, e.g. those of Bielschowsky, ${ }^{2}$ and Loewenberg and Malamud.11 In some places, particularly in the caudal parts of the putamen of our case, this external capsule scar was very heavy and the état marbré appeared to be merely a ramification of it (fig. 1b). A somewhat similar condition occasionally could be seen at the junction of the internal capsule with the caudate nucleus. It is true that in our cases, as well as in those previously published, ' marble' scars were seen which had no connexion with the scars in the adjacent white matter. Such occurrences call to mind the socalled putamen-claustrum type of large hæmorrhage, seen for the most part in hypertensive conditions.

How wrong it is to speak of état marbré as a striate system disease is shown by the widespread incidence of the lesions. They are to be found in globus pallidus (particularly in its efferent tracts, the lamellæ and ansa lenticularis), in the substantia nigra, where compact and reticulate zones are equally affected, in all subependymal regions of the ventricular system, in the dentate nucleus, in the olivary bodies, in the white matter of the cerebellum and to some extent in that of the cerebrum. Wherever one sees changes, they are qualitatively identical with those underlying the marble-formation-that is to say, more or less circumscribed glial scars often perivascularly arranged and with no signs of recent disintegration of tissue.

Hypermyelinized scars in the thalamus have been described with increasing frequency during recent years (A. Meyer, ${ }^{12}$ Gozzano, ${ }^{7}$ Loewenberg and Malamud, ${ }^{11}$ R. Holzer ${ }^{10}$ ), and our second case adds a fresh contribution, as, in addition to this, it is distinguished by the absence of a striatal ' marble state'. Etat marbré has also been found in the claustrum by Myslevecek. ${ }^{13}$ The sclerosis in the olivary body is of special interest because of a similar finding in van Bogaert's case, ${ }^{3}$ but in contrast with the latter no myoclonic twitchings were observed during life in ours.

The affection of the substantia nigra, associated with a considerable increase of Hallervorden-Spatz pigment in the reticulate zone, and also that 
of the dentate nucleus brings into discussion the possible relationship of état marbré with certain other conditions, particularly HallervordenSpatz disease (état dysmyélinisé) and the affection of the dentate-rubral system, observed in a case of athetosis by Bostroem and Spatz. A combination of état marbré and état dysmyélinisé has been recorded a few years ago by Onari, ${ }^{14}$ but what this coincidence means pathogenically and how often it occurs has not yet been satisfactorily explained-the less so, as the nosological interpretation of the changes in état dysmyélinisé becomes more and more complicated (Helfand ${ }^{25}$ ). We shall refer to the whole problem in a subsequent paper, dealing with état dysmyélinisé. The complexity and extent of the lesions in cases such as ours not only emphasize the difficulties of localization of clinical signs, such as athetosis, etc., but should make us very chary of regarding état marbré ('Vogt's disease ') as a unity, which can be diagnosed during life. A similar conclusion must be reached after considering the various theories propounded to explain the causation of état marbré. It seems to us that the nosological conceptions of this condition are based on far too few thoroughly examined cases, and might undergo considerable alteration with increasing experience.

\section{PATHOGENESIS}

The original view of C. and $\mathrm{O}$. Vogt, ${ }^{23}$ that état marbré is a malformation, has been abandoned by the great majority of writers (W. Scholz, ${ }^{18}$ Schwartz, ${ }^{19}$ A. Meyer, ${ }^{12}$ Myslevecek, ${ }^{13}$ Loewenberg and Malamud, ${ }^{11} R$. Holzer, ${ }^{10}$ etc.). An inflammatory origin was favoured by some workers (Bielschowsky, ${ }^{2}$ Loewenberg and Malamud, ${ }^{11}$ Case ${ }^{4}$ ), and trauma preceded one of the cases of Scholz. ${ }^{18}$ A constitutional factor has been suggested by cases of Anton, Oppenheim and C. Vogt, Scholz, ${ }^{18}$ Bielschowsky ${ }^{2}$ and van Bogaert. $^{3}$ Van Bogaert's case, however, was complicated by the presence of Unverricht-Lundborg disease. Schwartz ${ }^{19}$ was the first to suggest birth trauma as its cause, and this view has been strongly supported by several authors (Pfeiffer, ${ }^{16}$ Lotmar, ${ }^{27}$ etc.).

A review of the literature reveals, as far as we can discover, only 23 cases of état marbré which have been pathologically verified. In seven of these no birth history was given, and of the remaining 16 as many as nine showed definite signs of birth trauma. Among the positive cases we have included the first case of Loewenberg and Malamud and that of Case, although the authors themselves do not appear to attach any importance to the evidence of birth lesion. Nevertheless, impartial consideration of the history of both these cases makes it impossible not to consider birth trauma as a factor. The same applies to the previous case of $\mathbf{A}$. Meyer, in which a review of the history leaves no room for doubt that a definite birth injury occurred. The perivascular gliosis and endarteritis in this case, originally considered to be the result of an inflammatory process, can easily be interpreted as the result of anoxæmia (Pentschew ${ }^{15}$ ), and it needs no further discussion to be assured 
that the evidence in favour of an inflammatory process, in other socalled inflammatory cases, is based on similar histological findings. At this point we must make it clear that we do not accept evidence of birth trauma too easily. There must be a history of difficult or asphyxiate delivery followed by fits or other neurological symptoms in early infancy. Less serious'disturbances are discounted. Our collection of cases from the literature shows, furthermore, that cerebral lesions were thought to have been present from birth in 13 cases, whilst in a further seven cases there were apparently definite signs of the disease within the first year of life, although athetosis may have developed later in a few of them. The whole of this evidence strongly suggests that in the great majority of cases état marbré originates in prenatal, natal or very early postnatal life.

The figures given above are of interest in that they suggest that birth trauma, although it may admittedly not cover all cases, is an important ætiological factor in a considerable number of them. Perhaps it would be more relevant and more useful to look not for a uniform cause of état marbré, but for a uniform pathophysiological mechanism which might be common to several ætiologically different conditions. Such a view is the more attractive as it has been successfully applied to the related question of plaques fibromyéliniques. It has been shown by Spatz ${ }^{20}$ and his co-workers that plaques fibromyéliniques are brought about by such different diseases as $\mathrm{CO}$ poisoning, arteriosclerosis, hypertension, etc. A similar state of affairs may well apply to état marbré, which may turn out to be a pathological state of multiple ætiology. As regards its mechanism, two problems are of particular interest : that of the hypermyelinization of the scars, and that of their retiform arrangement and special localizatory predilection.

As regards the hypermyelinization, it has been made sufficiently clear by Spatz, Mittelbach, Pentschew and others, that small glial scars of elongated shape and vascular origin are essential to its production, but there is no unanimity of opinion as to the details of pathogenesis. The majority of writers hold the view that the excess of fibres has been brought about by regeneration. Bielschowsky ${ }^{2}$ has, however, suggested the idea of a production of myelin around originally naked axis-cylinders. His explanation is interesting in the light of our newly acquired knowledge of the myelogenetic function of glia. The excess of myelin would be, so to speak, a by-product of the pathological hyperactivity of the glia. The difficulties of interpretation of the histological picture are so great as to render exact histological proof of one or the other of these theories almost impossible.

It is equally difficult to account for the peculiar retiform arrangement of the scars and their predilective site. Although glial scars of a perivascular and patchy type are scattered over many regions of the brain, typical état marbré seems to occur most frequently in the striate body and in the cortex, and only rarely in the thalamus and other regions. Accordingly $\mathbf{C}$. and $\mathbf{O}$. Vogt suggested a ' pathoclitic' disposition of the striate body and the cortex. 
One must be aware, however, that this is more in the nature of a statement, useful though it may be, than an explanation of the problem, upon which only comprehensive comparative studies can hope to throw more light. In this effort Schwartz has led the way by relating état marbré to the lesions seen after birth trauma, but so far his histological evidence is superficial. Further systematic research on normal and pathological conditions of the newborn should be of value and might enable us to see early stages of état marbré. Although état marbré is almost exclusively a condition of the early epochs of life, it should also be looked for in vascular lesions of later years. There it might occur, as we find with plaques fibromyéliniques, in the form which Hallervorden ${ }^{8}$ has called the 'paradoxical appearance of status marmoratus without myelinization.' On this point only few and by no means convincing observations, notably by Gozzano ${ }^{7}$ and Stief, ${ }^{22}$ are as yet available. Berlucchi's ${ }^{1}$ recent description of structures simulating état marbré in the striate body of normal brains should be clearly distinguished from the definitely pathological hypermyelinized scar, here under discussion.

It might even be necessary to go back to more fundamental studies of the peculiarities of the blood supply in the regions affected. In this regard Schwartz's conception of the terminal vein determining localization in birth trauma has not been sufficiently utilized. As a further example we can take K. Stern's ${ }^{21}$ recent study of the extension of vascular lesions in the pons. His explanation of retiform lesions brings his paper particularly into discussion here. According to him, physical factors, as, for example, the degree of pressure of hæmorrhages and the differences in consistency of the tissue, are more important in determining the extension of lesions than is generally realized. The retiform structures studied by him have been brought about by a tendency for the large pontocerebellar fibres to be spared. We should do well to remember, however, that the resemblance between Stern's pictures and those of état marbré is only superficial. The état marbré differs not only in size, but also in the lack of spatial relationship between the preserved striopallidal bundles and the scars. On the other hand, retiform structures, comparable to those described by Stern, have been found in the putamen (outside the état marbré) and pons of our first case (figs. 2 and 4). Further research may prove whether we are dealing with more than a merely negligible similarity.

\section{SUMMARY}

1. Two personal cases are described, one of which showed an état marbré in the striate body, the other in the thalamus alone. Both cases were the subjects of severe mental defect and quadriplegia from infancy. The first patient suffered also from torsion spasm, generalized fits, athetosis and other involuntary movements and screaming attacks.

2. With the état marbré were associated lesions in the globus pallidus, black and red zone of the substantia nigra, subependymal regions, dentate 
nuclei and olivary body. The cortex was unaffected; the myelin sheaths of the white matter showed some slight diffuse or circumscribed lack of staining power.

3. The conception of état marbré as a nosological entity is criticized. Particular stress is laid on the importance of birth trauma in many cases, and further investigation in this field is urged. The pathogenesis of retiform lesions is discussed with reference to recent investigations.

We gratefully acknowledge our thanks to Dr. R. Mackenzie Stewart for furnishing us with the pathological material and clinical information of our second case, and to Mrs. A. Meyer for the preparation of the histological sections and microphotographs. Our thanks are also due to Dr. James Nicoll, Medical Superintendent of the Fountain Hospital, for permission to publish the first case, to Dr. F. Golla, Director of the Central Pathological Laboratories of the London County Mental Hospitals, for his kindly interest and to the Rockefeller Foundation for a grant to one of us (A. M.).

\section{REFERENGES}

1 Berlucchi, Carlo, Riv. di neurol., 1934, 7.

2 Bielschowsky, M., Jour. f. Psychol. u. Neurol., 1924, 31, 125.

3 Van Bogaert, Ludo, Revue neurol., 1929, $2,385$.

4 Case, Arch. of Neurol. and Psychiat., 1934, 31, 817.

5 Filiminoff, Zeits. f. d. g. Neurol. u. Psychiat., 1922, 78, 197.

6 DE GIacomo, Riv. pat. nerv. ment., 1925, 29, 791.

7 Gozzano, Riv. pat. nerv. ment., 1934, 43, 41 ; Riv. di neurol., 1934, 7, 1.

8 Hallervorden, Bumke's Handbuch, 1930, 11, 996.

9 Hiller, Arch. f. Psychiat., 1935, 103,.1.

10 Holzer, R., Zeits. f. d. g. Neurol. u. Psychiat., 1934, 151, 696.

11 Loewenberg and Malamud, Arch. of Neurol. and Psychiat., 1933, 29, 104.

12 Meyer, A., Zeits. f. d. g. Neurol. u. Psychiat., 1926, 100, 201.

13 MysleveceK, Zentralbl. f. d. g. Neurol., 1927, 45, 99 ; 1929, 52, 222.

14 Onari, Zeits. f. d. g. Neurol. u. Psychiat., 1925, 98, 457.

15 Pentschew, Arch. f. Psychiat., 1933, 101, 80.

16 Pfeiffer, Arch. f. Psychiat., 1925, 72, 728.

17 Scharapow and Tschernomordik, Jour. f. Psychol. u. Neurol., 1928, 35, 279.

18 Scholz, W., Zeits.f. d. g. Neurol. u. Psychiat., 1924, 88, 355.

19 Schwartz, Ph., Ergebn. inn. Med. u. Kinderheilk., 1927, 31, 367 ; Zeits. f. d. g. Neurol. u. Psychiat., 1924, 80, 263.

20 Spatz, H., Verhandl. d. Gesellsch. d. Nervenärzte, 1931, 53.

21 Stern, K., Zeits. f. d. g. Neurol. u. Psychiat., 1935, 152, 497.

22 Stref, Zeits.f. d. g. Neurol. u. Psychiat., 1924, 91, 579.

23 Vogt, C. and O., Jour.f. Psychol. u. Neurol., 1920, 25 (Ergänzungsband) ; Psychiat. neurol. Woch., 1926, 28, 85 ; Jour.f. Psychol. u. Neurol., 1928, 37, 387.

24 Vogt, C., Jour. f. Psychol. u. Neurol., 1912, 18, 479.

25 Helfand, M., Jour. Nerv. Ment. Dis., 1935, 81, 662.

26 Hallervorden, J., and Spatz, H., Zeits. f. d. g. Neurol. u. Psychiat., 1922, 79, 254.

27 Lotmar, F., Forts. d. Neurol. u. Psychiat., 1931, 3, 244. 